\title{
Electromyography (EMG) Signal Recognition Using Combined Discrete Wavelet Transform Based on Artificial Neural Network (ANN)
}

\author{
Moh Arozi ${ }^{1}$, Farika T Putri ${ }^{1}$, Mochammad \\ Ariyanto ${ }^{1}$, Wahyu Caesarendra ${ }^{1}$ \\ ${ }^{1}$ Mechanical Engineering Department \\ Faculty of Engineering, Diponegoro University \\ Semarang, Indonesia \\ *Email: arosiboy@gmail.com,
}

\author{
Augie Widyotriatmo ${ }^{2}$, Munadi ${ }^{1}$, Joga D. Setiawan ${ }^{1,3}$ \\ ${ }^{2}$ Faculty of Industrial Technology \\ ITB, Bandung \\ ${ }^{2}$ Mechanical Engineering Department. \\ Universiti Teknologi PETRONAS, \\ Kuala Lumpur, Malaysia
}

\begin{abstract}
Rapid disability patients increasing over time and need a solution in the future. Hand amputation is one form of disability that common in Indonesian society. A possible solution would be necessary at the moment is the development of prosthetic hand that has the ability as a human hand. The development of neuroscience has now reached the stage of the body's ability to use the signal as an input signal to operate a system. One of the applications of the science development is the use of electromyography (EMG) signals as an input to the control system to operate the prosthetic hand. This study is divided into two stages: a preliminary study and further research. Initial research focus in the process of EMG signal pattern recognition and advanced research focus in the development of a prototype prosthetic hand that is integrated with the controller system. Preliminary research indicates that the results of pattern recognition EMG signal using wavelet transform and Artificial Neural Network (ANN) classification has an accuracy rate of about $77.5 \%$. Based on these results, it can be concluded that the study results could be used as a signal input to program control of the prosthetic hand that will be developed in phase two.
\end{abstract}

Keywords-Electromyography; Pattern Recognition; Discrete Wavelet Transform; Artificial Neural Network.

\section{INTRODUCTION}

Increased human population that is sharp throughout the hemisphere raises issues that go with it, including in Indonesia. One of the problems that are present concurrently increase in human population, especially in Indonesia, is the issue of the increase in disability. One disability that often happens amid public is hand disability.

Emergence and development of biomedical engineering disciplines gives great hope to find solutions of various problems faced in the medical field including hand disability issues. This issue is increasing from year to year [1]. According to the concept, disability is a person whose state of physical or biological systems different from other people in general, which can be an obstacle for him to do something decent.

The issue of hands disability in Indonesia is the unavailability of active prosthetic hand, responsive and affordable for the general public. This argument is based on the fact that the prosthetic hand available is still passive [2] and expensive [3] and does not fit into the size of Indonesian's hands. Based on this reality, the development of prosthetic hand that are active, responsive, affordable, and appropriate size of Indonesian's hands can be a solution to the problem.

Availability of good signal input is one of the most importance aspects in a prosthetic hand development. EMG signal is one signal which can be used as input signals into a prosthetic hand system [4,5]. Artificial neural network [6,7], fuzzy classifiers, neuro-fuzzy classifiers [8] and the other based on probabilistic methods [9] are some of the classification method which widely used today. Wavelet transformation method, multi- resolution analysis of timefrequency based is the latest development for EMG signal analysis methods $[10,11]$. The ANN method is chosen because it is widely used and gives good performance in classification.

This initial research, based on the above explanation, focused to develop pattern recognition method for EMG signal which generate more accurate classification data. Improved accuracy of classification of data will improve the accuracy of the system control prosthetic hand developed.

The order of the experimental method in this study is shown in Fig. 1 below. The study begins with the process of data acquisition then followed by consecutive wavelet transformation, feature extraction and classification method that in studies using artificial neural network (ANN). 


\section{EXPERIMENTAL METHOD}

The order of the experimental method in this study is shown in Fig. 1 below. The study begins with the process of data acquisition then followed by consecutive wavelet transformation, feature extraction and classification method that studies using artificial neural network (ANN).

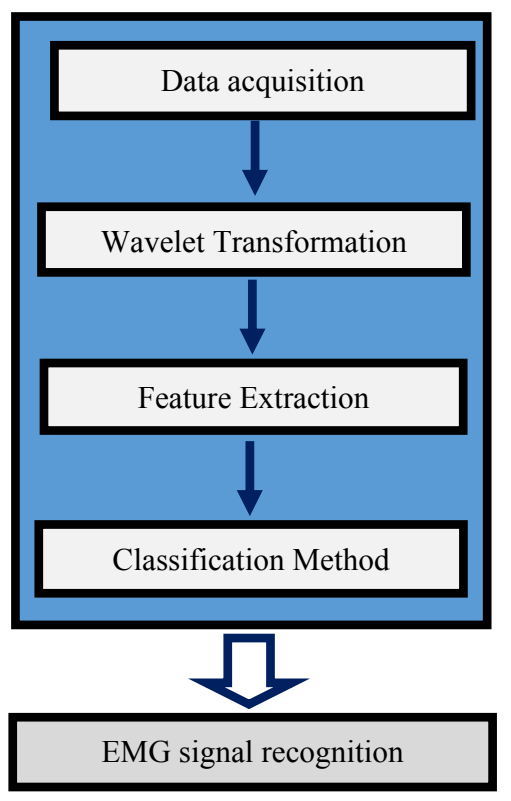

Fig. 1. Research Methodology

This study begins with the process of data acquisition. In this stage of data collection in the form of signals from the muscle activity of human hands using EMG sensors Thought Technology Infiniti FlexComp 10 channels. EMG data taken from the hand signal of flexor carpi radialis muscle. Muscle flexor carpi radial is one of three muscles that overall hand movement named the flexor digitorum superficialis muscle, flexor carpi radialis muscle and the extensor Carpi radialis longus muscle. Sensors are placed at a distance of $2 \mathrm{~cm}$ between the two sensors for the output signal. Position sensor placement can be clearly seen in Fig. 2. Data obtained from eight hand movements are hand open, close hand, mouse, keyboard, hand force, power grip, pinch and tripod as shown in Fig. 3.

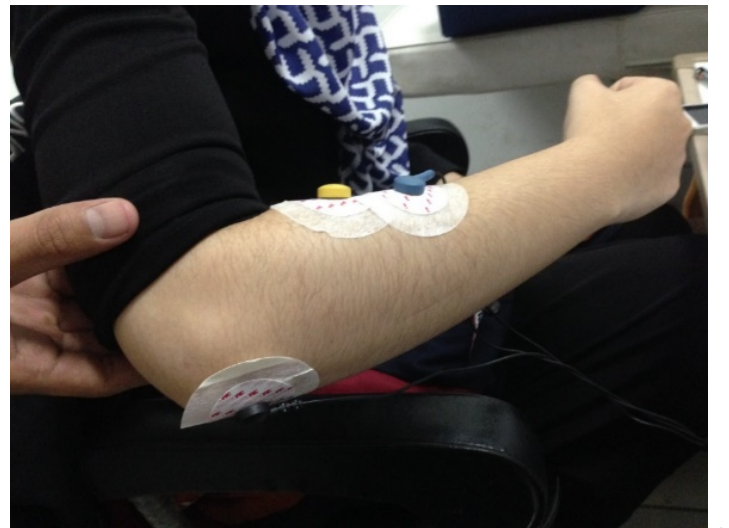

Fig. 2. EMG sensor placement in the flexor carpi radialis muscle.

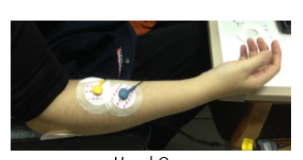

Hand Open

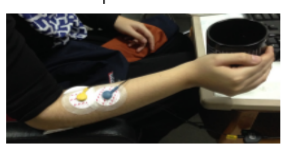

Powergrip

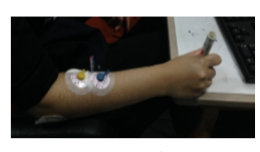

Tripod

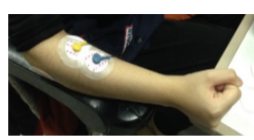

Hand Close

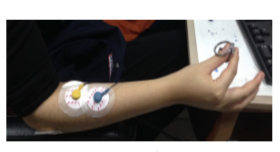

Pinch

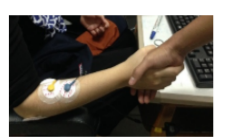

Handforce

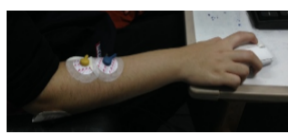

Mouse

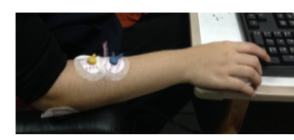

keyboard
Fig. 3. Eight hand movements that are used for data retrieval .

Wavelet transform used in this study is a discrete wavelet transform. The discrete wavelet transform method is a method of AMR to represent the time and frequency signals properly. Methods of discrete wavelet transform based signal Provides better speed than time-based methods such as RMS, Mean, SD and Fourier Transform [11]. The equation below is an equation to obtain discrete wavelet transform of a signal $x(n)$

$$
C(a, b)=\sum_{n \in Z} x[n] \psi_{a, b}[n]
$$

$a$ in the equation is the dilation or scale, $b$ is the translation and $\psi_{a}, b[\mathrm{n}]$ is a discrete wavelet-based function to which it obtained from the following equation,

$$
\psi_{a, b}[n]=\frac{1}{\sqrt{a}} \times \psi\left(\frac{n-b}{a}\right)
$$

The next step in the process of feature extraction which is useful information extracted from the EMG signal data. This process will differentiate movement signals with one another 
by way of add, locate and distinguish signal characteristics of the performed movements. Five feature extraction for EMG used in this study are three feature -based time domain ( Root Mean Square (RMS), kurtosis and skewness ) and two feature -based frequency, total power (TTP) and the mean power (MNP) . Here is an explanation of the fifth these features.

- Root Mean Square (RMS): RMS is one of time domain feature. RMS is a popular feature of used EMG signal analysis. RMS amplitude modulated modeled as Gaussian random process [12]. Equation (1) below is a model of RMS ,

$$
R M S=\sqrt{\frac{1}{N} \sum_{i=1}^{N} x_{i}^{2}}
$$

Where $N$ is number EMG signal and $x_{i}$ is the raw data EMG, while $i$ represent the interval data.

- Kurtosis: Kurtosis is a time domain-based feature. Kurtosis statistical method known as that used to describe the distribution and a feature that Identifies the tendency of peak data. Kurtosis data level is determined by comparing the peak of the curve inclination of data distribution and normal curve [12].

- Skewness: Skewness is one of the EMG signal feature that is included in the time domain feature. Skewness is defined as the inclination distribution data. The data is said to have a normal distribution when the location of the average value, the median value and the data mode on a line in the curve, if these values are not located in one line in the curve occurs the skewness or the heeling [12].

- Total Power (TTP): Total power include in frequency domain feature. Total power is defined as the total number of spectral density values for EMG signal [12].

- Mean Power (MNP): Mean power classified in time domain frequency. Mean power is defined as the average value of the density spectrum for EMG signal [12].

\section{RESULTS AND DISCUSSION}

Collecting data is obtained from fifteen people with each person performs eight movements and on every movement made eight times (which use five times the movement). EMG signal data for each modes are cut each segment in 2,000 and then plotted on graph based on time domain. Fig. 5 shows an example of the signal cutting mode for close hand. Results from cutting signals to signal any movement at all modes of movement can be seen in Fig. 6.

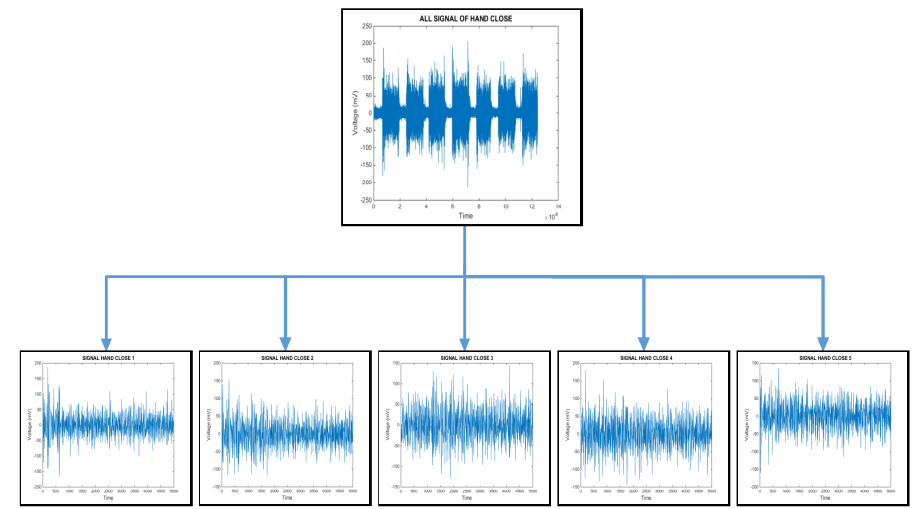

Fig. 5. Solving the signal from the signal five times the hand movements into signals each hand movement (an example of a closed hand mode ).
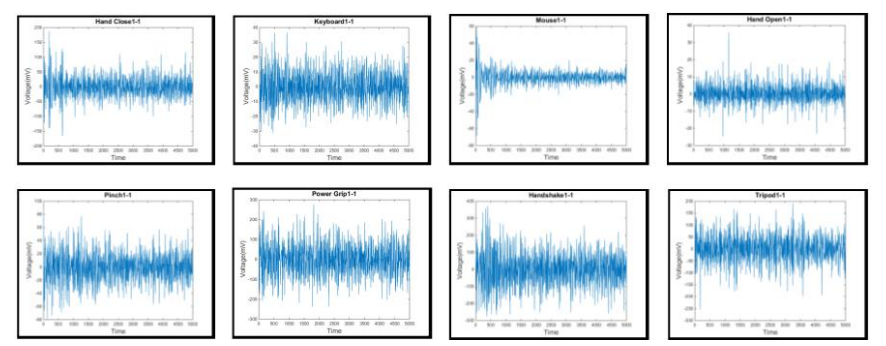

Fig. 6. Hand movement signals on all modes of movements.

The discrete wavelet transform is used in the next process to decompose the data based on the frequency. Discrete wavelet transform is performed using MATLAB software which decomposes each data into six classifications. Sample results from the discrete wavelet transform are shown in Fig. 7.

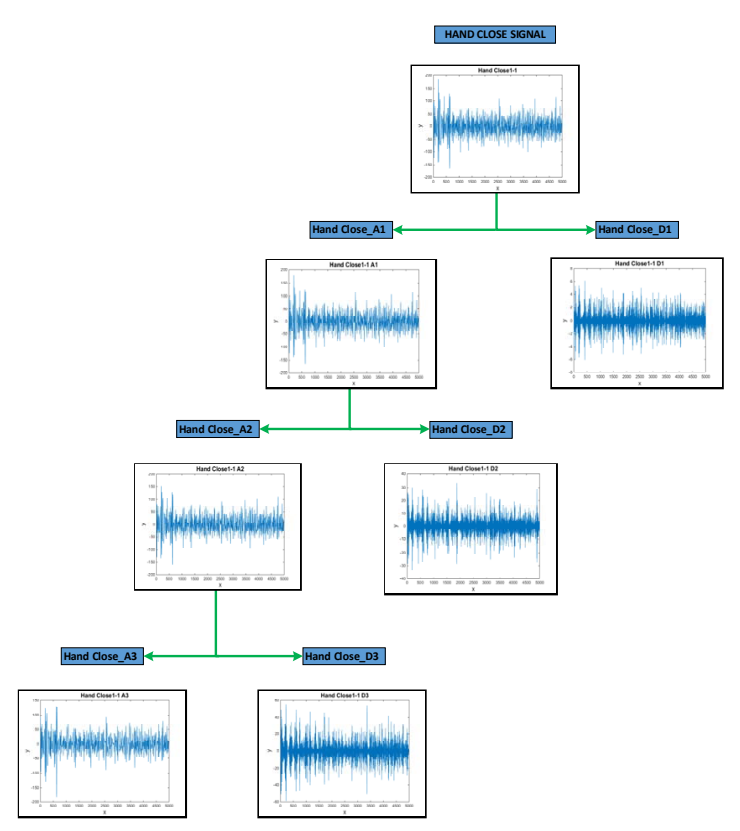



Electrical, Chemical Engineering (ICIMECE)

Fig. 7. Results of discrete wavelet transform in the frequency base to a closed hand mode

Five feature extraction that are RMS, kurtosis, skew ness, TTP and MNP are used to process the result from discrete wavelet transform. The feature extraction result is classified using Artificial Neural Network. The classification results for $\mathrm{D}_{1}, \mathrm{D}_{2}$, and $\mathrm{D}_{3}$ can be summarized as in Table I, Table II, and Table III respectively. Based on the classification results, the decomposed $\mathrm{D}_{1}$ gives the best accuracy than $\mathrm{D}_{2}$, and $\mathrm{D}_{3}$.

Based on the Table I, from the training results the lowest accuracy is Hand Close and the overall accuracy is $85.7 \%$. From the confusion testing result, the overall accuracy is 66.7 $\%$. From the overall classification result, the highest accuracy are Hand Open, Tripod, and Hand Force, while the lowest accuracy is Hand Close. The overall classification result in hand movement classification is $77.5 \%$.

TABLE I. TRAINING CLASSIFICATION RESULTS FOR DECOMPOSED D $\mathrm{D}_{1}$

\begin{tabular}{|l|c|c|c|c|c|c|c|c|}
\hline \multirow{2}{*}{$\begin{array}{c}\text { Finger } \\
\text { movement }\end{array}$} & \multicolumn{7}{|c|}{ True Classification } \\
\cline { 2 - 9 } & $\begin{array}{c}\text { Hand } \\
\text { open }\end{array}$ & Tripod & Pinch & $\begin{array}{c}\text { Power } \\
\text { grip }\end{array}$ & $\begin{array}{c}\text { Hand } \\
\text { close }\end{array}$ & $\begin{array}{c}\text { Hand } \\
\text { force }\end{array}$ & Mouse & $\begin{array}{c}\text { Key- } \\
\text { board }\end{array}$ \\
\hline $\begin{array}{l}\text { Hand } \\
\text { open }\end{array}$ & 5 & 0 & 0 & 0 & 0 & 0 & 0 & 0 \\
\hline Tripod & 0 & 5 & 0 & 0 & 0 & 0 & 0 & 0 \\
\hline Pinch & 0 & 0 & 3 & 0 & 0 & 0 & 0 & 0 \\
\hline $\begin{array}{l}\text { Power } \\
\text { grip }\end{array}$ & 0 & 0 & 0 & 2 & 2 & 0 & 0 & 1 \\
\hline $\begin{array}{l}\text { Hand } \\
\text { close }\end{array}$ & 0 & 0 & 0 & 0 & 1 & 0 & 0 & 0 \\
\hline $\begin{array}{l}\text { Hand } \\
\text { force }\end{array}$ & 0 & 0 & 0 & 0 & 0 & 3 & 0 & 0 \\
\hline Mouse & 0 & 0 & 0 & 0 & 0 & 0 & 3 & 0 \\
\hline $\begin{array}{l}\text { Key- } \\
\text { board }\end{array}$ & 0 & 0 & 0 & 1 & 0 & 0 & 0 & 2 \\
\hline $\begin{array}{l}\text { Accuracy } \\
\text { (\%) }\end{array}$ & 100 & 100 & 100 & 66.7 & 33.3 & 100 & 100 & 66.7 \\
\hline $\begin{array}{l}\text { Overall } \\
\text { accuracy } \\
\text { (\%) }\end{array}$ & & & 85.7 & & & \\
\hline
\end{tabular}

TABLE II. TESTING CLASSIFICATION RESULTS FOR DECOMPOSED D

\begin{tabular}{|l|c|c|c|c|c|c|c|c|}
\hline \multirow{2}{*}{$\begin{array}{c}\text { Finger } \\
\text { movement }\end{array}$} & \multicolumn{7}{|c|}{ True Classification } \\
\cline { 2 - 10 } & $\begin{array}{c}\text { Hand } \\
\text { open }\end{array}$ & Tripod & Pinch & $\begin{array}{c}\text { Power } \\
\text { grip }\end{array}$ & $\begin{array}{c}\text { Hand } \\
\text { close }\end{array}$ & $\begin{array}{c}\text { Hand } \\
\text { force }\end{array}$ & Mouse & $\begin{array}{c}\text { Key- } \\
\text { board }\end{array}$ \\
\hline $\begin{array}{l}\text { Hand } \\
\text { open }\end{array}$ & 0 & 0 & 0 & 0 & 0 & 0 & 0 & 0 \\
\hline Tripod & 0 & 0 & 0 & 0 & 0 & 0 & 0 & 0 \\
\hline Pinch & 0 & 0 & 1 & 0 & 0 & 0 & 0 & 0 \\
\hline $\begin{array}{l}\text { Power } \\
\text { grip }\end{array}$ & 0 & 0 & 0 & 2 & 1 & 0 & 0 & 1 \\
\hline $\begin{array}{l}\text { Hand } \\
\text { close }\end{array}$ & 0 & 0 & 0 & 0 & 0 & 0 & 0 & 0 \\
\hline $\begin{array}{l}\text { Hand } \\
\text { force }\end{array}$ & 0 & 0 & 0 & 0 & 0 & 0 & 0 & 0 \\
\hline Mouse & 0 & 0 & 0 & 0 & 0 & 0 & 0 & 0 \\
\hline $\begin{array}{l}\text { Key- } \\
\text { board }\end{array}$ & 0 & 0 & 0 & 1 & 0 & 0 & 0 & 1 \\
\hline
\end{tabular}

\begin{tabular}{|l|c|c|c|c|c|c|c|c|}
\hline $\begin{array}{l}\text { Accuracy } \\
\text { (\%) }\end{array}$ & $\mathrm{NaN}$ & $\mathrm{NaN}$ & 100 & 100 & 0 & $\mathrm{NaN}$ & $\mathrm{NaN}$ & 50 \\
\hline $\begin{array}{l}\text { Overall } \\
\text { accuracy } \\
\text { (\%) }\end{array}$ & \multicolumn{10}{|c|}{$\mathbf{6 6 . 7}$} \\
\hline
\end{tabular}

TABLE III. OVERALL CLASSIFICATION RESULTS FOR DECOMPOSED D

\begin{tabular}{|c|c|c|c|c|c|c|c|c|}
\hline \multirow{2}{*}{$\begin{array}{c}\text { Finger } \\
\text { movement }\end{array}$} & \multicolumn{8}{|c|}{ True Classification } \\
\hline & $\begin{array}{c}\text { Hand } \\
\text { open }\end{array}$ & Tripod & Pinch & $\begin{array}{c}\text { Power } \\
\text { grip }\end{array}$ & \begin{tabular}{|c} 
Hand \\
close
\end{tabular} & \begin{tabular}{|l} 
Hand \\
force
\end{tabular} & Mouse & $\begin{array}{c}\text { Key- } \\
\text { board }\end{array}$ \\
\hline $\begin{array}{l}\text { Hand } \\
\text { open }\end{array}$ & 5 & 0 & 0 & 0 & 0 & 0 & 0 & 0 \\
\hline Tripod & 0 & 5 & 0 & 0 & 0 & 0 & 0 & 0 \\
\hline Pinch & 0 & 0 & 4 & 0 & 0 & 0 & 1 & 0 \\
\hline $\begin{array}{l}\text { Power } \\
\text { grip }\end{array}$ & 0 & 0 & 0 & 4 & 4 & 0 & 0 & 2 \\
\hline $\begin{array}{l}\text { Hand } \\
\text { close }\end{array}$ & 0 & 0 & 0 & 0 & 1 & 0 & 0 & 0 \\
\hline $\begin{array}{l}\text { Hand } \\
\text { force }\end{array}$ & 0 & 0 & 1 & 0 & 0 & 5 & 0 & 0 \\
\hline Mouse & 0 & 0 & 0 & 0 & 0 & 0 & 4 & 0 \\
\hline Keyboard & 0 & 0 & 0 & 1 & 0 & 0 & 0 & 3 \\
\hline $\begin{array}{l}\text { Accuracy } \\
(\%)\end{array}$ & 100 & 100 & 80 & 80 & 20 & 100 & 80 & 60 \\
\hline $\begin{array}{l}\text { Overall } \\
\text { accuracy } \\
(\%)\end{array}$ & & & & & & & & \\
\hline
\end{tabular}

\section{CONCLUSSION}

The results showed that the research EMG data of hand movements, after going through the process of data acquisition and feature extraction, it can be used to identify the hand movement using ANN. The research produces up to $77.5 \%$ accuracy for overall classification. Based on the classification results, the decomposed $\mathrm{D}_{1}$ gives the best accuracy off all.

\section{REFERENCES}

[1] Pusat Data dan Informasi Departemen Kesehatan RI, Penyandang Disabilitas pada Anak,

http://www.depkes.go.id/resources/download/pusdatin/infodatin/infoda tin disabilitas.pdf (2014).

[2] Republika, Kaki Tangan Palsu Murah 'Made in' Bandung, http://nasional.republika.co.id/berita/nasional/jawa-baratnasional/13/04/04/mkoo9k-kaki-tangan-palsu-murah-made-inbandung, (2013).

[3] Jawa Pos, Siswadi Pemakai Tangan Bionic Pertama di Indonesia, http://www2.jawapos.com/baca/artikel/14055/Siswadi-PemakaiTangan-Bionic-Pertama-di-Indonesia, (2015).

[4] M. Khezri, M. Jahed, and N. Sadati, "Neuro-fuzzy surface EMG pattern recognition for multifunctional hand prosthesis control ", Industrial Electronics International Symposium, IEEE on, 4-7 June 2007, pp. 269- 274.

[5] Takamitsu Matsubara, Jun Morimot, "Bilinear Modeling of EMG Signals to Extract User-Independent Features for Multiuser Myoelectric Interface", IEEE Transactions On Biomedical Engineering, Vol. 60, No. 8, August 2013,pp. 2205-2213. 
[6] Rui Sun, Rong Song, Kai-yu Tong, "Complexity Analysis of EMG Signals for Patients after Stroke During Robot-Aided Rehabilitation Training Using Fuzzy Approximate Entropy", Transactions On Neural Systems And Rehabilitation Engineering, Vol. 22, No. 5, September 2014, pp-1013-1019

[7] M. Ariyanto et al., "Finger movement pattern recognition method using artificial neural network based on electromyography (EMG) sensor," 2015 International Conference on Automation, Cognitive Science, Optics, Micro Electro-Mechanical System, and Information Technology (ICACOMIT), Bandung, 2015, pp. 12-17.

[8] M. Khezri, M. Jahed, and N. Sadati, "Neuro-fuzzy surface EMG pattern recognition for multifunctional hand prosthesis control", Industrial Electronics International Symposium, IEEE on, 4-7 June 2007, pp. $269-274$

[9] A. D. C. Chan and K. B. Englehart, "Continuous myoelectric control for powered prostheses using hidden Markov models,", IEEE Transactions On Biomedical Engineering, vol. 52, pp. 121-124, 2005.

[10] Kevin Englehart, Bernard Hudgins, Philip A. Parker,"A WaveletBased Continuous Classification Scheme for Multifunction Myoelectric Control”, IEEE Transactions On Biomedical Engineering, Vol. 48, No. 3, March 2001, pp. 302-311.

[11] A. Subasi, "Classification of EMG signals using combined features and soft computing techniques", Application. Software Computing, Vol. 12, No. 8, Aug. 2012, pp. 21882198.

[12] Kuegler, P., S. Member, C. Jaremenko, J. Schalachelzki, 2013, "Automatic Recognition of Parkinson Disease Using Surface Electromyography During Standarized Gait Test," IEEE, No. 4208 pp. 5781-5784. 